\title{
Dilemas do processo \\ de gestão descentralizada da vigilância sanitária no Estado do Rio de Janeiro
}

\author{
| 'Mirian Miranda Cohen |
}

Resumo: Com a criação do Sistema Único de Saúde, em 1990, o Ministério da Saúde tomou as primeiras medidas para descentralizar as ações de vigilância sanitária, o que significou decisiva inovação na tradicional institucionalidade dessa área e grande desafio para os gestores nos três níveis da Federação. Os efeitos dessa determinação somente foram sentidos após criação da Agência Nacional de Vigilância Sanitária, em fins de 1999, quando foi possível estruturar o atual Sistema Nacional de Vigilância Sanitária numa concepção que incentiva o papel diretor, coordenador e executor das açôes de maior complexidade das Secretarias Estaduais de Saúde. Este estudo analisa a descentralização da gestão da VISA empreendida pela Secretaria de Estado de Saúde do Rio de Janeiro no período 2002-2006 e as condiçõos das Secretarias Municipais no exercício das respectivas funções, através de pesquisa baseada em análise dos relatórios de avaliação da descentralização elaborados pelo Centro de Vigilância Sanitária. Entre as conclusōes, destaca a fragilidade da própria Secretaria de Saúde do estado para assumir os encargos a ela atribuídos e questóes subjacentes ao exercício municipal. Tais constataçōes refletem as muitas dificuldades enfrentadas nas relações intergovernamentais diante do imperativo de as partes agirem solidariamente numa área fundamental para a saúde individual e coletiva e para o bemestar da população. $\mathrm{O}$ estudo informa requisitos básicos do processo de estruturação de um órgão de VISA e constitui importante contribuição para melhor compreender os entraves políticos, institucionais, técnicos, materiais e humanos que desafiam os gestores, para implementar as inovações ensejadas com a descentralização neste complexo campo.

> Palavras-chave: Sistema Único de Saúde; vigilância sanitária; descentralização.
'Analista de Gestão em Saúde/ Coordenadora da Qualidade DIPLAN/Fiocruz. Mestre e Doutoranda em Saúde Pública (ENSP/Fiocruz). Endereço eletrônico: mcohen@fiocruz.br.

Recebido em: 23/06/2008 Aprovado em: 01/09/2008 


\section{Introdução}

Este estudo aborda alguns aspectos relacionados ao processo de descentralização da gestão da vigilância sanitária (VISA) e de sua tradução concreta, a transferência de funções executoras e de responsabilidade gestora para municípios no estágio atual de implantação do Sistema Nacional de Vigilância Sanitária (SNVS). A partir do caso do Estado do Rio de Janeiro, discute as condições de implantação de um dos modelos de descentralização da VISA identificados no país, desencadeado a partir da promulgação da Constituição Federal de 1988, das publicações das normas reguladoras do SUS, dos pactos de saúde e, especificamente, da criação da Agência Nacional de Vigilância Sanitária (ANVISA) e normalização do SNVS.

Foram estudadas condições contextuais assinaladas como relevantes na constituição do perfil que o processo de descentralização das ações de VISA tem assumido no nível local, visando, através do caso estudado, alcançar o objetivo de identificar as particularidades dos contextos locais que interferem no processo de descentralização, mormente aquelas relacionadas ao modelo de gestão estadual da VISA no Sistema Único de Saúde (SUS), às condições de estruturação dos órgãos municipais de VISA e de acumulação da capacidade gestora, com destaque para os fatores que interferem na distribuição de responsabilidade entre as esferas de governo.

A amplitude do debate sobre VISA e seu processo de descentralização pode ser percebida em sua própria abrangência conceitual. A Lei Orgânica do SUS, no 8.080 de 1990, estabelece que a Vigilância Sanitária (VISA) está voltada para proteção da saúde, tendo entre suas atribuições a regulação de um amplo e diversificado conjunto de produtos e serviços agrupados em grandes ramos Alimentos; Medicamentos; Saneantes; Cosméticos; Serviços de Saúde; Insumos e Correlatos -, além do controle sanitário dos portos, aeroportos e fronteiras, que cabe exclusivamente à União realizar.

A relevância pública desse vasto campo de objetos requer variadas capacidades técnicas e rigor no exercício do poder de polícia sanitária que lhe é inerente. De fato, a natureza das responsabilidades da VISA impóe que as ações sejam desenvolvidas exclusivamente por agentes públicos dado que se voltam precipuamente para a proteção do coletivo em detrimento dos interesses particulares, pois cabe a esses agentes aplicarem as sanções legais pertinentes em caso de infrações que ponham em risco a saúde da população. Estes aspectos estão presentes e 
interferem no processo de descentralização dessas ações, pois exigem maior mobilização de recursos técnicos e políticos para sua efetivação.

Devido à complexidade das ações de VISA, é natural que a estrutura e organização dos órgãos encarregados de executá-las enfrentem problemas muito difíceis de resolver na prática. No entanto, dificuldades adicionais derivam da própria trajetória da VISA, pois, além da baixa ou nula prioridade política historicamente a ela concedida, tem sido pautada por traços como tradicionalismo, cartorialismo, centralização, verticalidade e ritualismo, o qual conduziu a uma generalizada situação nacional de ineficiência e desaparelhamento dos órgãos da vigilância sanitária nos três níveis de governo (LUCCHESE, 2001; ROZENFELD, 2000).

Com a implantação do SUS, desencadeou-se um amplo debate sobre o "dever ser” da VISA, e várias iniciativas foram empreendidas para sua reestruturação. Mas foi com a criação da ANVISA, e por iniciativa ou patrocínio desta, que têm sido incessantes as atividades destinadas a aprimorar a área e implantá-la descentralizadamente no país. Além de múltiplas diretrizes políticas, técnicas e normativas emitidas pela ANVISA, têm sido instituídos variados foros de discussão, como por exemplo, a I Conferência Nacional de Vigilância Sanitária (2001); Simpósios Nacionais de Vigilância Sanitária (SIMBRAVISA); Fóruns Regionais de VISA; Consultas Públicas promovidas pela ANVISA; Grupos de Trabalho integrados por acadêmicos e técnicos (GT VISA/ABRASCO); Centros Colaboradores de VISA instituídos em cooperação entre ANVISA e institutos de ensino e pesquisa (CECOVISA) e outros, além do crucial Plano Diretor de VISA (PDVISA), publicado em 2007. Um dos grandes desafios apontados nos documentos gerados nestes espaços de debate e formulação de propostas é a ressignificação das diretrizes e princípios do SUS para a área, bem como a expansão do processo de descentralização.

Todavia, é muito difícil consolidar uma rede tão complexa como a compreendida no SNVS, mesmo tendo transcorrido quase duas décadas desde a implantação do SUS no país. Com efeito, tal como se afirma no PDVISA,

se por um lado, esse Sistema está normativamente delineado, por outro, sofreu o que poderíamos chamar de reestruturação incompleta, visto que apenas seu componente federal foi reformulado no tocante à estrutura administrativa, à autonomia financeira e à estabilidade gerencial. (ANVISA, 2007, p. 20).

Isto se aplica obviamente às secretarias estaduais e municipais, que ainda enfrentam inúmeros obstáculos para assumir com autonomia e competência as 
respectivas responsabilidades gestoras. E o Estado do Rio de Janeiro não escapa a essa situação. Nesta perspectiva, este artigo examina o processo de descentralização das ações de VISA da Secretaria Estadual de Saúde do Rio de Janeiro (SES-RJ) para os municípios do estado e as condições destes para assumirem os encargos correspondentes, abordando os seguintes tópicos: 1. Métodos e técnicas de pesquisa; 2. Descentralização das Ações de VISA: pressupostos do SNVS; 3. A Vigilância Sanitária no Estado do Rio de Janeiro; e 4. Gestão Municipal na descentralização da VISA.

\section{Método e técnicas de pesquisa}

O estudo baseou-se fundamentalmente em análise documental e notas de trabalho de campo da autora. Este compreende o período de 2002 a 2006, que fornece elementos para a análise do modelo de descentralização adotado pelo estado, sendo os dados de diagnóstico dos órgãos municipais restritos aos últimos dois anos. As fontes documentais consistiram em relatórios de avaliação produzidos pelo Centro de Vigilância Sanitária (CVS) da SES-RJ, os quais registram as estratégias desenhadas, as diretrizes efetivadas e os resultados alcançados na articulação com os municípios para fins da descentralização. Tais documentos são: (1) Programa de Descentralização das Ações de VISA no Estado do RJ (SES-RJ, 2002); (2) Diagnóstico Situacional da VISA no Estado (SES-RJ 2002; 2006); (3) Relatório de Avaliação das Ações de VISA no Município (SES-RJ, 2005); (4) Relatório de Acompanhamento das Ações Descentralizadas (SES-RJ, 2005); (5) Planilha de Desenvolvimento das Ações de VISA pelos municípios (SES-RJ, 2005); (6) Fluxograma de Supervisão das Ações Descentralizadas (SES-RJ, 2006); (7) Relatórios de Gestão do CVS. (SES-RJ, 2006). Quanto às notas de campo, foram recolhidas durante o acompanhamento profissional do processo de descentralização nos 92 municípios do estado. As normas estaduais reguladoras do processo de descentralização (SES-RJ, 1990; 1998) também são objeto deste trabalho, já que orientam o processo de descentralização no período estudado.

A respeito das avaliações efetuadas pela SES-RJ, é preciso esclarecer que os municípios não receberam tratamento diferenciado; todos foram analisados utilizando indiscriminadamente o mesmo conjunto de parâmetros. Os requisitos referentes à gestão municipal foram neste estudo agrupados em cinco blocos: Estrutura legal (legalização do órgão municipal de VISA); Estrutura física e Organizacional (organização e coordenação da VISA municipal); Recursos 
(materiais, humanos e financeiros disponíveis na VISA municipal); Normas de Acompanhamento e Controle (padronização e instrumento de registro das atividades utilizado pelos órgãos municipais no estado); Ações Realizadas (ações de VISA executadas pelos municípios do estado).

Para fins de análise, na apresentação dos resultados foram definidas duas dimensôes relativas à capacidade gestora dos entes envolvidos no processo de descentralização: Gestão Estadual, analisada no terceiro tópico, e Gestão Municipal, analisada no quarto tópico.

A ênfase deste estudo está nas formas de condução do processo de descentralização setorial, a partir das seguintes questôes: quais as estratégias priorizadas no processo de descentralização das ações de VISA no estado? Quais resultados tangiveis do processo de descentralização da VISA podem ser identificados no Estado do Rio de Janeiro?

\section{Descentralização das Ações de VISA: pressupostos do SNVS}

O termo descentralização, já bastante debatido na literatura sobre o SUS, tem neste trabalho o foco tanto na discussão acerca do processo de regionalização e municipalização, como na definição de responsabilidades entre os entes federativos, ou seja, descentralização como estratégia de melhor distribuição das atribuições compartilhadas de vigilância sanitária. Parte-se do suposto de que a descentralização das ações de VISA resultará em maior impacto para a proteção da saúde da população se as responsabilidades entre os gestores do SUS forem pactuadas e implementadas de forma integrada entre os entes federativos, sendo que aquele que pretende descentralizar, repassando responsabilidades técnicoadministrativas e políticas, deve assumir encargos, inclusive econômicofinanceiros, para garantir a viabilidade do processo.

Segundo Arretche (1999), a descentralização depende da implementação de estratégias deliberadas dos níveis mais abrangentes de governo, que pretendem transferir responsabilidades ao nível local, a fim de favorecer a adesão à proposta. A descentralização das políticas sociais é vista como estratégia para a democratização das instituiçõos e a aproximação dos cidadãos aos centros de decisões de seu interesse, sendo deste modo apreendida como instrumento adequado para o uso e a distribuição mais eficiente dos recursos. Assim, várias iniciativas foram empreendidas, fortemente motivadas por este mito presente em um quadro típico dos anos 90, onde aflora a preocupação com o gasto público e a eficiência (ARRETCHE, 1996). 
No entanto, este sempre foi um grande desafio à gestão da VISA, visto que o processo de descentralização da saúde no Brasil tem contemplado prioritariamente a assistência, área que concentra a maioria dos recursos financeiros alocados para o setor, além de expressiva demanda em todos os segmentos de atenção. As sucessivas edições de Normas Operacionais do SUS, ao regulamentar as atividades da assistência, reforçaram este entendimento (LUCCHESE, 2000; 2001; COHEN, 2006).

As normas editadas em diferentes versões foram: NOB 01/91 e 92; NOB 01/93; NOB 01/96 e NOAS SUS 01/02. Estas abordam especificamente alguns aspectos do desenvolvimento das políticas de saúde e não de todo o sistema, e apresentam diferenças fundamentais que refletem o momento político em que foram elaboradas e a intensidade do processo de pactuação entre gestores para sua formulação.

A Proteção e a Promoção à Saúde, previstos constitucionalmente, não são mencionadas na NOB SUS 01/91 nem na sua substituta, a NOB SUS 01/92, que omite a Vigilância Sanitária e a Epidemiológica. A NOB SUS 01/93, assim como sua antecessora, não teve impacto direto sobre a área de Vigilância Sanitária, apesar de sua importância inquestionável na implementação do processo de descentralização das ações de saúde. Como principais implementaçôes na NOB SUS 01/93, pode-se apontar o início do repasse "fundo a fundo" para municípios habilitados e o estabelecimento das instâncias intergestoras (Comissão Intergestores Bipartite - CIB e Comissão Intergestores Tripartite -CIT).

A NOB/96 pretende atender às demandas pela assistência e às exigências sanitárias, o que lhe confere caráter inovador frente a suas antecessoras. Inova ao introduzir o Piso Básico de Vigilância Sanitária (PBVS), inserido como parte variável do Piso de Atenção Básica, assim como, ao descrever, mesmo de forma genérica, as atribuições de cada gestor nas três esferas de governo no tocante à Vigilância Sanitária. A partir de 1998, os municípios passaram a receber recursos do PBVS repassados fundo a fundo, calculados por sua base populacional, referida pelo IBGE no valor de 0,25 centavos per capita/ano. Segundo Mendes (2001), a NOB/ 96 contribuiu para a consolidação da proposta, no momento hegemônica na organização do SUS, de municipalização autárquica.

Paralelamente à implantação do SUS, uma das várias iniciativas empreendidas para a reestruturação da VISA foi a Portaria no 1.565 , do Ministério da Saúde, de 26 de agosto de 1994, que definiu o Sistema Nacional de Vigilância Sanitária (SNVS), sua abrangência, as competências das três esferas de governo e as bases da 
descentralização. Porém, a efetivação dessa norma foi prejudicada devido a fatores como a descontinuidade político-administrativa, tendo o sistema de esperar até sua revisão em 2000, ano em que, pela Lei no 9.782, de 1999, entra em funcionamento a Agência Nacional de Vigilância Sanitária (ANVISA), que ficou incumbida da coordenação do SNVS.

$\mathrm{Na}$ implementação desse sistema, a Portaria SAS no 18, de 21 de janeiro de 1999, que, segundo o modelo preconizado na assistência, classificava as ações de VISA em baixa, média e alta complexidades, teve importante contribuição. Apesar de polêmica, esta Portaria continua sendo a referência utilizada pelos órgãos de VISA, ao discutir seus procedimentos. Com base neste arranjo, em relação aos estados federados instituíram-se os Termos de Ajustes e Metas (TAM), firmados com a ANVISA, com repasse das Taxas de Fiscalização Sanitária (TFVS) e das Ações de Média e Alta Complexidade em VISA (MAC/VISA), respectivamente, a partir de agosto de 2000 e outubro de 2001. Ademais, aos estados foram destinados os recursos dos municípios não habilitados a receber o repasse fundo a fundo.

Este movimento coincide com o momento de implementação da Norma Operacional de Assistência à Saúde, NOAS 2001/2002, que pretende conformar sistemas funcionais, com serviços hierarquizados e equidade no acesso. Seu avanço na área está em propor, para a sistematização do processo de habilitação dos municípios, alguns requisitos relativos à Vigilância Sanitária. Com a NOAS, buscouse reforçar o nível estadual, aumentar a capacidade de gestão do sistema e a cooperação entre os entes federados, enfatizando-se a regionalização e a hierarquização da rede de serviços, seguindo assim as diretrizes da Programação Pactuada e Integrada (PPI), que é um instrumento de planejamento e coordenação das ações intermunicipais efetivado após a implantação da NOB/SUS 96 em 1998 (COHEN; LIMA; ANDRADE, 2006). Esse período demarca fortalecimento do papel estadual, favorecendo a ação do órgão de VISA neste nível de gestão.

A partir de 2004, através da Portaria no 2.473/2003, da ANVISA, os municípios foram incluídos nacionalmente no processo de pactuação das ações de média e alta complexidades em VISA. Dentre seus objetivos, destacam-se: proporcionar melhores condições de gestão nos três níveis de governo; definir os objetivos organizacionais nas unidades da Federação, direcionando-as para a realização de metas finalísticas de promoção e proteção à saúde da população e efetivar o Subsistema Nacional de Vigilância Sanitária de acordo com os preceitos do SUS. Ademais, este ampliou os 
recursos dos municípios considerados aptos, nos estados, a pleitear a habilitação ao TAM que tiveram seus pleitos aprovados na CIB e validados na CIT, mas não alterou a lógica de repasse, que permaneceu sendo per capita. Este período demarca uma nova etapa da construção do SNVS, com ampliação da discussão da política de descentralização e financiamento da VISA, culminando com sua incorporação na pactuação da vigilância em saúde.

No entanto, a necessidade de reforço dos princípios organizativos do SUS, assim como o diagnóstico de fragmentação, pulverização e má utilização de recursos, entre outros aspectos, levaram à revisão do processo de regulação da gestão descentralizada. Assim, instituiu-se o Pacto pela Saúde 2006, através da Portaria no 399/GM, de 22 de fevereiro de 2006, que aprovou suas diretrizes operacionais. O propósito era estabelecer uma normativa nacional menos complexa, mais flexível e baseada em regras gerais, capaz de consolidar a descentralização do sistema na perspectiva da solidariedade, da cooperação e da autonomia entre os entes federados. Entre os objetivos do Pacto, está redefinir responsabilidades coletivas por resultados sanitários em função das necessidades de saúde da população (compromissos, metas e prioridades) e na busca da equidade social. Segundo o documento oficial, as mudanças estão na gestão por compromissos solidários; na regionalização, como eixo estruturante da descentralização, no financiamento integrado e na unificação dos pactos.

Com o Pacto em 2006, houve a revisão das formas de financiamento do SUS, com definição de concentração dos repasses de recursos federais em cinco blocos de financiamento: Atenção Básica; Atenção de Média e Alta Complexidades; Vigilância em Saúde; Assistência Farmacêutica e Gestão do SUS. E os recursos de vigilância sanitária, no bloco vigilância em saúde, passaram a ser da ordem de $\mathrm{R} \$ 0,32$ (trinta e dois centavos) habitante/ano. Sua relevância na implementação da gestão descentralizada da VISA está nas inovações que impõem a organização setorial, impulsionando a articulação entre as diferentes instâncias e setores de prestação de serviços de saúde.

Apesar de a Lei Orgânica do SUS destacar como atribuição comum às diferentes esferas de governo a função de definir as instâncias e mecanismos de controle e fiscalização relativos ao poder de polícia sanitária, o Pacto, nas suas dimensões pela Vida e de Gestão, também sintetiza as atribuições dos entes federativos e define, no campo da promoção e proteção à saúde, três áreas: Vigilância Epidemiológica, Vigilância Sanitária e Vigilância Ambiental, integradas no eixo definido como Vigilância em Saúde. Nessa normativa, a divisão de responsabilidade na Gestão se 
dá através do Termo de Compromisso de Gestão (TCG), que é a declaração pública dos compromissos assumidos pelo gestor na condução do processo de aprimoramento e consolidação do SUS. Este deve ser aprovado no Conselho de Saúde (da respectiva esfera de gestão), na Comissão Intergestores Bipartite (CIB) e Comissão Intergestores Tripartite (CIT). O quadro 1 sintetiza a distribuição de responsabilidades entre os níveis de gestão na VISA no que se refere ao TCG.

\section{Quadro 1. Responsabilidades das três esferas de governo em relação à Vigilância em Saúde}

\begin{tabular}{|c|c|c|}
\hline Termo de Compromisso de Gestão Federal & $\begin{array}{c}\text { Termo de Compromisso de Gestão } \\
\text { Estadual }\end{array}$ & $\begin{array}{l}\text { Termo de Compromisso } \\
\text { de Gestão Municipal }\end{array}$ \\
\hline $\begin{array}{l}\text { Coordenar e executar as ações de vigilância em } \\
\text { saúde, compreendendo as ações de média e alta } \\
\text { complexidades desta área, de acordo com as } \\
\text { normas vigentes e pactuações estabelecidas. } \\
\text { Coordenar, nacionalmente, as ações de } \\
\text { prevenção e controle da vigilância em saúde que } \\
\text { exijam ação articulada e simultânea entre os } \\
\text { estados, Distrito Federal e municípios. } \\
\text { Proceder à investigação complementar ou } \\
\text { conjunta com os demais gestores do SUS em } \\
\text { situação de risco sanitário. } \\
\text { Apoiar e coordenar os laboratórios de saúde } \\
\text { pública - Rede Nacional de Laboratórios de Saúde } \\
\text { Pública/RNLSP - nos aspectos relativos à } \\
\text { vigilância em saúde. } \\
\text { Assumir transitoriamente, quando necessário, a } \\
\text { execução das ações de vigilância em saúde nos } \\
\text { estados, Distrito Federal e municípios, } \\
\text { comprometendo-se em cooperar para que } \\
\text { assumam, no menor prazo possível, suas } \\
\text { responsabilidades. } \\
\text { Apoiar técnica e financeiramente os estados, o } \\
\text { Distrito Federal e os municípios, para que } \\
\text { executem com qualidade as ações de vigilância } \\
\text { em saúde, compreendendo as ações de vigilância } \\
\text { epidemiológica, sanitária e ambiental, de acordo } \\
\text { com as normas vigentes e pactuações } \\
\text { estabelecidas. } \\
\text { Monitorar e avaliar as ações de vigilância em } \\
\text { saúde, realizadas pelos municipios, Distrito } \\
\text { Federal, estados e pelo gestor federal, incluindo } \\
\text { a permanente avaliação dos sistemas de } \\
\text { vigilância epidemiológica e ambiental em saúde. }\end{array}$ & $\begin{array}{l}\text { Coordenar e executar as ações de } \\
\text { vigilância em saúde, } \\
\text { compreendendo as ações de média } \\
\text { e alta complexidades desta área, de } \\
\text { acordo com as normas vigentes e } \\
\text { pactuações estabelecidas. } \\
\text { Assumir transitoriamente, quando } \\
\text { necessário, a execução das ações de } \\
\text { vigilância em saúde no município, } \\
\text { comprometendo-se em cooperar } \\
\text { para que o município assuma, no } \\
\text { menor prazo possivel, sua } \\
\text { responsabilidade. } \\
\text { Executar algumas aç̃̃es de vigilância } \\
\text { em saúde, em caráter permanente, } \\
\text { mediante acordo bipartite e } \\
\text { conforme normatização específica. } \\
\text { Supervisionar as ações de } \\
\text { prevenção e controle da vigilância } \\
\text { em Saúde, coordenando aquelas } \\
\text { que exigem ação articulada e } \\
\text { simultânea entre os municípios. } \\
\text { Apoiar técnica e financeiramente os } \\
\text { municípios, para que executem com } \\
\text { qualidade as ações de vigilância em } \\
\text { saúde, compreendendo as ações de } \\
\text { vigilância epidemiológica, sanitária e } \\
\text { ambiental, de acordo com as } \\
\text { normas vigentes e pactuações } \\
\text { estabelecidas. } \\
\text { Monitorar e avaliar as ações de } \\
\text { vigilância em saúde, realizadas pelos } \\
\text { municípios e pelo gestor estadual. }\end{array}$ & $\begin{array}{l}\text { Todo município deve: } \\
\text { assumir a gestão e } \\
\text { execução das ações de } \\
\text { vigilância em saúde } \\
\text { realizadas no âmbito local, } \\
\text { de acordo com as normas } \\
\text { vigentes e pactuações } \\
\text { estabelecidas, } \\
\text { compreendendo as ações } \\
\text { de: } \\
\text { a) vigilância } \\
\text { epidemiológica; } \\
\text { b) vigilância sanitária; } \\
\text { c) vigilância ambiental. } \\
\text { Elaborar a programação da } \\
\text { atenção à saúde, incluída a } \\
\text { assistência e vigilância em } \\
\text { saúde, em conformidade } \\
\text { com o plano municipal de } \\
\text { saúde, no âmbito da } \\
\text { Programação Pactuada e } \\
\text { Integrada da Atenção à } \\
\text { Saúde. } \\
\text { Monitorar e avaliar as } \\
\text { ações de vigilância em } \\
\text { saúde, realizadas em seu } \\
\text { território, por intermédio } \\
\text { de indicadores de } \\
\text { desempenho, envolvendo } \\
\text { aspectos epidemiológicos } \\
\text { e operacionais. }\end{array}$ \\
\hline
\end{tabular}

Fonte: Termos de Compromisso de Gestão - Responsabilidades das três esferas de governo em relação à Vig. em Saúde - ANVISA/2006 (http://www.anvisa.gov.br/Institucional/pdvisa/ TCG_Responsabilidades) - Adaptação da autora. 
Note-se que as atribuições são compartilhadas e complementadas pelos entes federativos. Todavia, a ação de programação e planejamento das ações de vigilância em saúde a serem estabelecidas no TCG é restrita aos municípios, fortalecendo seu papel executor vinculado à busca de melhores resultados.

Em que pesem todas as questôes apontadas acima, muitas das dificuldades de implementação da descentralização das ações de VISA estão nas relaçōes estabelecidas entre os diversos componentes do SNVS, compreendendo as seguintes instâncias: Ministério da Saúde, ANVISA, Conselho Nacional de Secretários Estaduais de Saúde (CONASS), Conselho Nacional de Secretários Municipais de Saúde (CONASEMS), Centros de Vigilância dos Estados, do Distrito Federal e dos Municípios, Laboratórios Centrais de Saúde Pública (LACENS), Instituto Nacional de Controle de Qualidade (INCQS) da Fundação Oswaldo Cruz, além dos Conselhos de Saúde dos estados, municípios e Distrito Federal no concernente ao controle social. E ainda deve-se articular com outras instituições, como PROCON, Ministério Público, Defensoria Pública, Tribunais de Contas, Ouvidorias e poderes Legislativo e Judiciário. É fácil deduzir que um arranjo sistêmico e ordenado envolvendo instâncias de tal importância e abrangência no ordenamento jurídicoadministrativo brasileiro não constitui tarefa fácil.

Neste arranjo, a ANVISA assumiu funções eminentemente de coordenação, regulação e fiscalização. Todavia, as novas normas não eliminaram as diretrizes estabelecidas pela Lei Orgânica do SUS, nº 8.080/90, para a área da VISA, no que diz respeito às responsabilidades e prerrogativas dos três níveis de governo e a centralidade do município, com a ressalva de que, nas diretrizes relativas à descentralização da VISA, é atribuído inicialmente papel protagonista aos estados, fato que lhes confere caráter excepcional no âmbito do SUS. Logicamente, as tensões entre gestores, no arranjo conferido à descentralização das ações de VISA, estão constantemente presentes.

A política nacional de descentralização embora se apresente no discurso da ANVISA como prioridade na conformação do sistema parece ter problema, um deles é a relação conflituosa entre estados e municípios, particularmente entre os municípios das capitais das unidades federadas e o estado da federação. (SOUTO, 2004).

No entanto, se o processo de descentralização na vigilância sanitária é ainda hoje marcado, de um lado, por incertezas quanto a seu alcance e implicaçóes, ele tem, por outro, se revelado um campo fértil de experiências inovadoras, seja quanto 
às propostas de integração setorial com pactos unificados, ou na diferenciação da participação do ente estadual, também como executor das ações ou ainda em relação ao arranjo pactuado na relação intergestores.

\section{A Vigilância Sanitária no Estado do Rio de Janeiro}

O Estado do Rio de Janeiro possui um amplo parque de indústrias, serviços públicos e estabelecimentos de saúde. Além disso, o território foi dividido em oito regiões de governo: Metropolitana, Noroeste Fluminense, Norte Fluminense, Serra; Baixadas Litorâneas, Médio Paraíba, Centro-Sul Fluminense e Costa Verde. Nessa linha, a SES-RJ chegou a propor a criação de nove regiões na saúde, mas que não foi formalizada, continuando a manter toda sua estrutura administrativa centralizada. Em 2007, a população do estado alcançava 15.420 .375 habitantes (IBGE, 2007), sendo que a Região Metropolitana, com 19 municípios (20,6\%), concentrava $74,7 \%$ da população, aí incluídos os 6,1 milhões de habitantes da capital Rio de Janeiro. Além disso, 32 municípios (34,8\%) têm menos de 20 mil habitantes e detêm apenas 2,76\% da população.

Cabe salientar que o município do Rio de Janeiro conta com excepcional cobertura, tanto no setor produtivo como de serviços, por ter sido a capital do país, contrariamente às carências e desigualdades de toda ordem observadas entre as regiōes e, dentro delas, entre os municípios. Contudo, essas disparidades não foram consideradas no processo de descentralização das ações de VISA iniciado pela SES-RJ com base na Resolução n ${ }^{\circ}$. 562, de 1990, que transferiu a responsabilidade pela execução de ações de baixa complexidade, comércio de alimentos em particular, a todos os municípios por igual. Nesse período o órgão estadual contava com uma precária estrutura física, estando totalmente desaparelhado e contando apenas com uma pequena equipe de trabalhadores carentes de investimentos em sua capacitação e de condições de trabalho.

Lucchese (2001) identifica uma importante relação da Vigilância Sanitária com muitos setores da economia, em função de seu potencial para implementar o valor da qualidade, nos produtos sob seu controle, assim como nas relações sociais que envolvem toda a cadeia da produção ao consumo de produtos e serviços de interesse para a saúde, fatores que muitas vezes obstaculizam o desenvolvimento das ações precípuas da área. 
Com o advento de diversas calamidades no campo da saúde púbica ocorridas no final da década de 90 no país, com focos localizados também no Estado do Rio de Janeiro, a Vigilância Sanitária passa a ser incluída na agenda de prioridades do governo estadual, assim como se destaca no cenário nacional. Foram diversas as irregularidades assinaladas, como: medicamentos falsificados, fábricas de "fundo de quintal”, distribuidoras clandestinas, farmácias comerciais e de manipulação envolvidas numa complexa trama articulada a roubo de cargas de medicamentos (COSTA, 2004).

[...] os escândalos das falsificações e outros problemas graves que aconteciam principalmente na área dos medicamentos e dos serviços de saúde, nos meses finais de 1997, fizeram a sociedade, e o Estado também, tomar conhecimento da importância da vigilância sanitária. Ela saía, finalmente, da marginalidade. (LUCCHESE, 2001).

Com a mobilização da sociedade, que exigia uma vigilância sanitária mais forte e atuante, o órgão estadual pode contar com uma conjuntura mais favorável, que o permitiu reunir os recursos básicos para a revisão de seu processo de trabalho (LUCCHESE, 2001; PIOVESAN, 2005). Entretanto, os avanços obtidos pelos órgãos estaduais de Vigilância Sanitária foram mais sentidos a partir da política de descentralização deflagrada pela Agência Nacional de Vigilância Sanitária, que, diferentemente do modelo adotado para a assistência à saúde, investiu prioritariamente na esfera estadual, fortalecendo seu papel de coordenador do sistema. Esse fato conformou um novo desenho no nível estadual do SUS, onde a área de Vigilância Sanitária obteve de modo acelerado maior destaque institucional. No Estado do Rio de Janeiro, o então Centro de Vigilância Sanitária da Secretaria de Estado de Saúde era chamado pelos demais setores de "primo rico", devido à revisão de sua estrutura e organização interna, que permitiu que este tivesse melhores condiçôes para gerenciar e aplicar seus recursos, melhorando sua estrutura física, seus processos de trabalho e ampliando e qualificando sua equipe multiprofissional.

Isto foi possível porque a lógica de financiamento por procedimentos típicos de convênios foi rompida após a criação da ANVISA, quando foram estabelecidos repasses financeiros regulares e automáticos para os entes federativos. A SES-RJ passou a receber repasses financeiros regulares da ANVISA, o que foi vital para sua reestruturação, visto que os recursos provenientes das taxas da vigilância sanitária nunca foram repassados àquela pela Secretaria Estadual de Fazenda. Esses recursos 
destinaram-se às ações de média e alta complexidades, cujo processo de pactuação entre os três níveis de governo se expressou no TAM. Desde então, diferentes e múltiplos movimentos político-estratégicos foram se configurando na área, permitindo que a SES-RJ pudesse rever o processo de descentralização das ações de vigilância sanitária. Assim, ao retomar este movimento em 1998, mediante a Resolução $\mathrm{n}^{\circ} 1.262$, a SES-RJ delegou competências aos municípios para atuarem na vigilância sanitária de serviços de saúde sem internação e estabelecimentos de comércio farmacêuticos, bem como realizar a concessão e revalidação de licença de funcionamento, cassação de licença de funcionamento e fiscalização dos mesmos. Desta vez, os gestores locais foram chamados a se manifestar sobre a abrangência da descentralização e a decidir sobre a adesão ou não a esse processo. $\mathrm{Na}$ época, somente 25 municípios aderiram à proposta, sendo que, destes, apenas 14 atenderam às condições da pactuação. Apesar dessa limitação, os compromissos pactuados significaram sem dúvida um marco na VISA estadual.

$\mathrm{O}$ aprendizado neste processo levou à reflexão de que o amplo debate e a tomada de decisão mediante instrumentos democráticos por si só não são capazes de garantir a consecução da proposta. É necessário que mecanismos de apoio e de acompanhamento do processo de descentralização sejam efetivados. Inicialmente, foi criado um espaço de articulação entre o CVS e os órgãos municipais de VISA, o Núcleo de Planejamento e Desenvolvimento Institucional (NPDI), que teve papel preponderante na organização da descentralização, acompanhando e apoiando os municípios e facilitando a interlocução com as áreas técnicas da SES.

Outras iniciativas incluíram a incorporação das ferramentas do planejamento em suas dimensões política, técnica e gerencial; capacitação do corpo técnico; criação de instrumentos para integração com os municípios; articulação com instituições de ensino e pesquisa, sobretudo na produção de conhecimentos para VISA, capacitação, fomento à pesquisa e suporte técnico às ações; revisão do processo de trabalho; instauração de instrumentos de controle, monitoramento e avaliação das ações descentralizadas, e outras medidas destinadas a fortalecer o papel coordenador do gestor estadual. A ideia era construir uma trajetória menos normativa e mais alicerçada na capacidade de governo dos entes municipais. Nesse sentido, foram adotadas numerosas medidas visando a ampliar as competências, com expressivo investimento na qualificação dos profissionais e no estabelecimento de laços de confiança entre os membros do SEVS. 
O conjunto de estratégias formuladas provocou a movimentação interna do órgão estadual que, dessa forma, teve as demandas ampliadas e diversificadas, as quais foram atendidas na medida em que se pôde contar com uma equipe maior e mais especializada. Entretanto, entre as estratégias previstas estava a transferência de recursos da SES-RJ para os municípios, o que não se concretizou, sendo o único recurso regularmente repassado aquele oriundo do Termo de Ajustes e Metas (TAM).

Mesmo para organizar o nível local para execução das ações básicas de VISA, não foi possível concretizar o repasse de recursos financeiros pela SES-RJ. Na realidade, entre os suportes previstos para implementação do processo de descentralização, o único que fugia à governabilidade do CVS era o repasse de recursos financeiros aos municípios conforme o teto mínimo per capita ou Piso Básico Estadual de VISA. Isto ocorreu devido à impossibilidade de o então CVS/ SES-RJ reunir os recursos políticos necessários para efetivar os repasses, apesar da existência de verba e demais requisitos legais e técnicos para tanto. Este foi um obstáculo imposto ao processo de descentralização, mas não foi o único nem aquele que, sem dúvida, possa ser definido como mais importante, visto que muitas vezes os municípios que apresentavam maiores necessidades de recursos para a área eram exatamente aqueles cujos repasses federais específicos do PBVS não eram destinados ao setor e seu gerenciamento era desconhecido pelo coordenador do órgão local.

Para superar este obstáculo, o órgão estadual propôs a transferência de recursos materiais (equipamentos, veículos, insumos) aos municípios, que na prática foi inviabilizada por problemas relacionados à morosa tramitação administrativa na SES-RJ, sendo irregular a concretização das entregas de bens considerados essenciais. Como resultante, no processo de descentralização, o nível local ficou descoberto em matéria de apoio material e financeiro. Esta situação, apesar de não ser relevante para grande parte dos municípios do estado, a exemplo de sua capital, foi decisiva para as unidades menores, carentes de todo tipo de recursos.

Quanto ao suporte logístico para a própria VISA estadual, foram várias as atividades desenvolvidas, desde as melhorias das instalações físicas e compra de equipamentos e insumos, até a qualificação do quadro de pessoal. Assim, também houve investimento na estruturação física e administrativa do CVS, o qual proporcionou melhores condições de trabalho e agilidade na interação com os municípios. Entre 1999 e 2005, houve empreendimentos tais como aquisição de equipamentos de informática, contratação de empresas para locomoção dos técnicos 
e ampliação do quadro de pessoal, que praticamente triplicou - sobretudo o de nível superior, que passou de 84 para 256 profissionais, com incremento de 204,8\% no período. Seus processos de trabalho foram revistos para que houvesse espaço na agenda para as atividades de coordenação do SEVS.

Ao estruturar o órgão estadual para que os municípios pudessem avançar na pactuação das ações de média e alta complexidades, as diversas estratégias empreendidas foram articuladas e ampliados os esforços de integração com os órgãos municipais de VISA e demais participantes do SEVS, principalmente os LACENS e o INCQS, pois seria necessária ampliação do suporte laboratorial no estado com a adesão dos municípios ao TAM.

O grande desafio residia no fato de o CVS/SES/RJ sempre ter sido o executor principal destas açôes, sendo apenas delegada aos poucos municípios mais equipados a realização de ações de inspeção sanitária em indústria de alimentos. As ações de média e alta complexidades nas áreas de produtos farmacêuticos e serviços de saúde permaneciam sob a responsabilidade exclusiva do estado. Não havia uma cultura disseminada no estado de açóes municipais nesses ramos de atividades. No entanto, inicialmente, 18 municípios foram considerados aptos a apresentar seus pleitos e 11, após terem os projetos aprovados na CIB-RJ e na CIT, foram habilitados à execução de um conjunto mínimo de atividades que compreendia, além das ações básicas já desenvolvidas, a atuação nas seguintes áreas: Unidades Básicas de Saúde (inclui os estabelecimentos odontológicos); Estabelecimentos de Atenção ao Idoso; Laboratórios Clínicos e Postos de Coleta; Estabelecimentos de Radiodiagnóstico; Distribuidoras, Drogarias e Farmácia de Manipulação; Cozinhas Industriais e Induistrias de Alimentos Dispensados de Registro; Salão de Beleza, Esteticistas, Academias de Ginásticas e Congêneres.

Para dar suporte aos municípios que aderiram ao TAM, diversas estratégias foram empreendidas, a maioria voltada à qualificação dos profissionais do SEVS e a harmonização dos procedimentos de VISA no estado.

Em relação às funções de coordenação da SES-RJ, houve uma série de atividades, entre elas, reuniōes com o Conselho de Secretários Municipais de Saúde do Estado do Rio de Janeiro (COSEMS-RJ); oficinas periódicas com as coordenações locais de VISA; oficinas regionais de vigilância sanitária; supervisão aos municípios com entrega posterior do respectivo relatório; capacitação; inspeçõos conjuntas em estabelecimentos sujeitos à ação de VISA com técnicos dos municípios; grupos 
temáticos para harmonização de procedimentos; assídua comunicação e intercâmbio de ideias que garantiram fluxo contínuo de informações; visitas da SMS a SES-RJ, etc. Este processo sempre foi aberto a todos os municípios, por compreender-se que aqueles que ainda não aderiram ao TAM estavam se qualificando para tal. Assim, não obstante as muitas dificuldades, os resultados alcançados no processo de descentralização das ações de VISA foram significativos. Entre os produtos mais importantes, destacam-se os apresentados no quadro abaixo, que sintetiza estratégias, suportes e produtos. 
Quadro 2. Gestão das açóes descentralizadas no Estado do Rio de Janeiro:

estratégias, suportes e produtos, 2002-2006

\begin{tabular}{|c|c|c|}
\hline Estratégia & Apoio Logístico & Produtos \\
\hline $\begin{array}{l}\text { Harmonização dos } \\
\text { procedimentos. }\end{array}$ & Realização de 11 Grupos Temáticos. & $\begin{array}{l}\text { Roteiros de inspeção; manuais e } \\
\text { procedimentos operacionais padrão. }\end{array}$ \\
\hline $\begin{array}{l}\text { Formalização de } \\
\text { espaços de } \\
\text { articulação, } \\
\text { pactuação, } \\
\text { capacitação de } \\
\text { gestores e avaliação } \\
\text { do processo de } \\
\text { descentralização. }\end{array}$ & $\begin{array}{l}\text { Estruturação física e administrativa do } \\
\text { órgão estadual. } \\
\text { Criação de setor específico para } \\
\text { acompanhamento dos órgãos municipais } \\
\text { de VISA. } \\
\text { Realização de oficinas mensais com os } \\
\text { órgãos municipais. } \\
\text { Realização de reuniões periódicas com } \\
\text { COSEMS/RJ. } \\
\text { Participação nas reuniões da CIB. }\end{array}$ & $\begin{array}{l}\text { Programação Pactuada e Integrada (PPI) de } \\
\text { VISA. } \\
\text { Habilitação de } 11 \text { órgãos de VISA municipais } \\
\text { para desenvolvimento de ações de media } \\
\text { complexidade, segundo o Termo de Ajustes } \\
\text { e Metas da ANVISA. } \\
\text { Publicação de Resolução estadual de } \\
\text { descentralização das ações de VISA. } \\
92 \text { órgãos municipais e o órgão estadual } \\
\text { integrados. } \\
\text { Gestores municipais capacitados. }\end{array}$ \\
\hline $\begin{array}{l}\text { Pactuação e } \\
\text { avaliação Regional. }\end{array}$ & $\begin{array}{l}\text { Realização de oficinas descentralizadas de } \\
\text { VISA. }\end{array}$ & $\begin{array}{l}\text { Perfil regional das VISAs municipais. } \\
23 \text { Eventos de capacitação em VISA, } \\
\text { segundo perfil regional. }\end{array}$ \\
\hline $\begin{array}{l}\text { Supervisão aos } \\
\text { órgãos municipais de } \\
\text { VISA }\end{array}$ & $\begin{array}{l}\text { Visita técnica de equipe multiprofissional. } \\
\text { Formação e capacitação da equipe de } \\
\text { supervisão. }\end{array}$ & $\begin{array}{l}\text { Fluxograma e cronograma de supervisão. } \\
\text { Questionário de avaliação das ações } \\
\text { descentralizadas. } \\
03 \text { Diagnóstico das VISAs municipais. } \\
1 \text { Relatório de supervisão ao município por } \\
\text { ano. } \\
1 \text { Relatório estadual de aval iação das ações } \\
\text { descentralizadas por ano. } \\
1 \text { Equipe de supervisão capacitada. }\end{array}$ \\
\hline $\begin{array}{l}\text { Monitoramento e } \\
\text { avaliação das ações } \\
\text { descentralizadas. }\end{array}$ & $\begin{array}{l}\text { Criação da área técnica de } \\
\text { monitoramento e avaliação das ações } \\
\text { descentralizadas em setor especifico de } \\
\text { acompanhamento dos órgãos municipais } \\
\text { de VISA }\end{array}$ & $\begin{array}{l}\text { Programa de descentralização da VISA. } \\
\text { Metodologia para acompanhamento das } \\
\text { ações descentralizadas. } \\
\text { Banco de dados para monitoramento e } \\
\text { avaliação. }\end{array}$ \\
\hline $\begin{array}{l}\text { Capacitação dos } \\
\text { profissionais de VISA } \\
\text { no Estado do Rio de } \\
\text { Janeiro. }\end{array}$ & $\begin{array}{l}\text { Eventos de capacitação promovidos e/ou } \\
\text { patrocinados pelo órgão estadual de VISA. } \\
\text { Inspeção conjunta com profissionais dos } \\
\text { órgãos municipais aos estabelecimentos } \\
\text { sujeitos ao controle da VISA } \\
\text { Convênios com instituição de ensino e } \\
\text { pesquisa }\end{array}$ & $\begin{array}{l}19 \text { Eventos de capacitação realizados. } \\
88 \% \text { dos profissionais municipais e } 100 \% \\
\text { dos estaduais de VISA capacitados. } \\
74 \% \text { dos Gestores de VISA capacitados. } \\
08 \text { Pesquisas fomentadas. } \\
\text { Participação em } 100 \% \text { dos cursos de } \\
\text { especialização em VISA de produtos } \\
\text { farmacêuticos e de serviços de saúde } \\
\text { realizados pela ENSP/Fiocruz. }\end{array}$ \\
\hline
\end{tabular}

Fonte: NPDI/CVS/SES - RJ (2002; 2005; 2006). 
Foram várias as estratégias empreendidas que objetivaram a consolidação do SEVS; o caminho percorrido foi o da qualificação e integração dos componentes deste sistema. Assim, apesar de o Pacto de Saúde encerrar o processo para habilitação de estados e municípios ao SUS, trazendo novos critérios de avaliação por resultados e engendrar novos desafios à gestão estadual no processo de condução da descentralização, os caminhos percorridos no estado que rompe com um processo de descentralização burocrático e opta por um processo subsidiado pelo pacto entre gestores vão ao encontro dessa proposta.

\section{Gestão municipal na descentralização da VISA}

A descentralização municipal, marco da política de saúde no Brasil, tem certamente introduzido um conjunto de alterações no desenho da engenharia institucional do setor, permitindo ao nível local maior poder de decisão sobre os rumos da política setorial. No entanto, por si só, mesmo considerando as induções normativas e até operacionais, a descentralização das ações de saúde não garante a efetiva execução das ações descentralizadas.

Em pesquisa realizada pela ANVISA (2000), com o objetivo de conhecer aspectos estruturais da organização e do desenvolvimento das ações de VISA nos municípios, foi apontada enorme disparidade entre porte, economia e estrutura dos municípios, reforçando as diversidades enfrentadas. Exemplo disto são as concentrações da população nas grandes cidades, que constituem sérios problemas em assuntos classificados como de ações básicas e de média complexidade (fiscalização sanitária de bares, restaurantes e supermercados; escolas; creches; consultórios dentário; asilos etc.) que exigem um mínimo de estrutura para serem executadas.

Assim, este estudo avança ao analisar a estrutura dos órgãos municipais de VISA, apresentando os parâmetros de avaliação da estruturação dos órgãos municipais de Vigilância Sanitária aplicados pelo Estado do Rio de Janeiro para mediar o processo decisório na descentralização dessas ações. Estes são apresentados em cinco blocos.

\section{Estatuto legal da Vigilância Sanitária}

A legalização dos órgãos de VISA é desafio a ser enfrentado na consolidação do SEVS, visto sua relevância para tornar válidos os atos de fiscalização sanitária. Entretanto, o processo de estruturação legal do órgão de VISA nos municípios, 
além de muito demorado, pois vem sendo implantado desde 1990, ainda se encontra bastante incompleto, conforme se verifica na tabela 1 .

Tabela 1. Implantação da estrutura legal do órgão de VISA nos municípios do Estado do Rio de Janeiro, 2005-2006

\begin{tabular}{lc}
\hline Legalização do órgão municipal de VISA & \% municípios \\
\hline Inclusão do órgão de VISA no organograma da SMS & 79 \\
Código Sanitário & 67 \\
Ato de investidura do coordenador & 64 \\
Documento de criação do órgão de VISA & 48 \\
Vinculação hierárquica da VISA ao gabinete do SMS & 27 \\
\hline
\end{tabular}

Fonte: Elaborado a partir de NPDI/CVS-SES-RJ, (2005; 2006). Diagnóstico Situacional dos Órgãos Municipais de Vigilância Sanitária do Estado do Rio de Janeiro.

Apesar de em todos os municípios existir um órgão de VISA, muitos ainda não são formalmente constituídos. É bastante problemática a existência de $52 \%$ dos órgãos municipais de VISA na ilegalidade, por não terem sido formalmente criados. Tal fato é agravado pela persistência de 33\% dos órgãos municipais sem código sanitário e pela não-nomeação de $36 \%$ dos coordenadores. É inaceitável que funcionários públicos exerçam uma função típica de Estado sem pleno respaldo legal, pois suas atuações poderão ser objeto de contestaçôes e das sanções correspondentes.

Os aspectos jurídicos que envolvem a questão começam a ser discutidos com a ampliação do escopo de atuação dos órgãos municipais, que passam a ser minimamente responsabilizados pela execução do conjunto de ações básicas de VISA. Em decorrência, o estado, para enfrentar essa problemática, ofertou curso de capacitação em direito sanitário para gestores e técnicos municipais de vigilância sanitária, onde este tópico foi inserido de modo pragmático. Ademais, a equipe estadual de supervisão aos órgãos de VISA foi capacitada para dar suporte aos municípios no processo de formalização do órgão. Todavia, dada a amplitude do problema que envolve o executivo e o legislativo municipal, é vital a sensibilização do gestor municipal e sua atuação junto ao Conselho Municipal de Saúde, para enfrentamento deste desafio. 


\section{Estrutura física e organizacional}

Entre as reivindicações dos gestores municipais de VISA, inclui-se a viabilização de espaço físico necessário ao desenvolvimento de trabalho da equipe multiprofissional. Em grande parte dos municípios, a estrutura, quando existente, é precária e se assemelha a um depósito, onde são guardados equipamentos e insumos destinados à ação de campo dos agentes que atuam no combate ao mosquito da dengue e a vetores, visto que frequentemente essas atividades são atribuídas ao órgão de VISA. Além disso, é comum em pequenos municípios a constituição de uma mesma equipe para desenvolvimento das açôes de vigilância, o que encontrou respaldo no formato adotado pelo ente federal na conformação da Secretaria de Vigilância em Saúde.

Em suma, em relação à estrutura física, os resultados são alarmantes: apenas $34 \%$ dos municípios possuem área física adequada ao desenvolvimento de suas funções, conforme pode ser verificado na tabela 2.

Tabela 2. Estrutura organizacional e física do órgão de VISA nos municípios do Estado do Rio de Janeiro, 2005-2006

\begin{tabular}{lc}
\hline Organização & \% de municípios \\
\hline Vinculação formal da VISA à estrutura da SMS & 80 \\
Vinculação hierárquica da VISA ao Gabinete do SMS & 37 \\
Área física adequada & 34 \\
\hline
\end{tabular}

Fonte: Elaborado a partir de: NPDI/CVS-SES-RJ, (2005; 2006). Diagnóstico Situacional dos Órgãos Municipais de Vigilância Sanitária do Estado do Rio de Janeiro.

Apesar da informalidade que se depreende dos percentuais da tabela, a grande maioria (80\%) dos órgãos de VISA já faz parte do desenho organizacional das Secretarias Municipais de Saúde (SMS). Este resultado é relevante na medida em que confirma que a área tem sido assumida enquanto função precípua do SUS. No entanto, cabe atentar para a existência de municípios onde a área de fiscalização sanitária foi atribuída a outra estrutura administrativa municipal e não à Saúde, por sua capacidade arrecadatória, enquanto o órgão de VISA lotado na SMS se limita às açôes educativas. Este é um desafio que precisa ser analisado e enfrentado no SUS. 
Outro dilema frequentemente presente nas discussões em torno da estrutura organizacional da VISA tem a ver com sua posição hierárquica na Secretaria de Saúde: deve subordinar-se ao gabinete do secretário ou à instância intermediária? As informações examinadas revelam que apenas 37\% dos órgãos municipais de VISA estão vinculados ao gabinete do Secretário Municipal de Saúde. Isto é considerado um problema, já que o ideal, segundo aponta Lucchese (2001), é a vinculação institucional direta ao gabinete do secretário, devido aos objetos de trabalho da VISA estarem inseridos no contexto das relaçóes produtivas, comerciais e de consumo e, portanto, serem afetados pelas pressóes de fortes interesses privados.

No que diz respeito à coordenação dos órgãos municipais, os dados são mais animadores, como mostra a tabela 3 .

Tabela 3. Institucionalização da coordenação do órgão de VISA nos municípios do Estado do Rio de Janeiro, 2005-2006

\begin{tabular}{lc}
\hline \multicolumn{1}{c}{ Perfil da coordenação } & \% de municípios \\
\hline $\begin{array}{l}\text { Coordenação instituída } \\
\text { Coordenadores com conhecimento sobre o Piso Básico de Vigilância }\end{array}$ & 96 \\
Sanitária - PBVS & 74 \\
Coordenadores investidos oficialmente na função & 64 \\
Coordenadores concursados (efetivos) & 60 \\
Experiência de gestão dos coordenadores (>1 ano) & 50 \\
Categoria profissional dos coordenadores -Médico Veterinário & 38 \\
\hline
\end{tabular}

Fonte: Elaborado a partir de: NPDI/CVS-SES-RJ, (2005; 2006). Diagnóstico Situacional dos Órgãos Municipais de Vigilância Sanitária do Estado do Rio de Janeiro.

Observa-se que em 96\% dos órgãos municipais há uma coordenação instituída, o que denota elevação do grau de institucionalização da VISA, embora apenas $64 \%$ dos coordenadores estejam investidos na função. Em relação ao tempo de experiência dos coordenadores, $50 \%$ deles têm menos de um ano no cargo. Contudo, o dado deve ser analisado com cautela, por causa das eleiçóes municipais ocorridas no período de coleta dos dados. Embora normalmente nessas épocas ocorra a substituição de funcionários em cargos de confiança nos altos escalões, a informação 
revela a dificuldade de se manter quadros técnicos qualificados nas funções de VISA. Este fato, por sua vez, prejudica seriamente a continuidade das estratégias traçadas e desestimula o investimento em qualificação profissional.

Foram oferecidas três turmas do Curso de Gestão em Vigilância Sanitária para Dirigentes Municipais, elaborado e ministrado em conjunto pelo CVS/SES-RJ e o Centro Colaborador de Vigilância Sanitária - Ensp/Fiocruz, e alguns dos coordenadores foram afastados das funçôes ainda durante a realização do mesmo, por sustentarem posição ética diante de fatos permeados por interesses políticos. Diferentemente da conquista de estabilidade de seus dirigentes obtida pela ANVISA em sua criação, um dos dilemas apresentados aos coordenadores dos órgãos municipais e mesmo estaduais de VISA é a constante ameaça de afastamento de suas funções diante de entraves provocados por ingerência política no desenvolvimento de suas ações. Essa descontinuidade traz prejuízos importantes à consolidação do SEVS e, certamente, à harmonização dos procedimentos de VISA essenciais ao processo de descentralização, visto que seu avanço depende da mobilização dos gestores em torno de sua concretização (SOUTO, 2004).

\section{Recursos materiais, humanos e financeiros}

\section{MATERIAIS}

$\mathrm{Na}$ tabela 4, poderá ser observado que os recursos materiais para a VISA não estão disponíveis em mais da metade dos municípios.

Tabela 4. Distribuição de recursos materiais disponíveis nos órgãos de VISA dos municípios do Estado do Rio de Janeiro, 2005-2006

\begin{tabular}{lc}
\hline \multicolumn{1}{c}{ Recursos materiais } & \% municípios \\
\hline Pelo menos uma linha telefônica & 90 \\
Pelo menos um computador & 48 \\
Arquivo de processos na VISA & 47 \\
Pelo menos um veículo disponível & 44 \\
\hline
\end{tabular}

Fonte: Elaborado a partir de: NPDI/CVS-SES-RJ, (2005; 2006). Diagnóstico Situacional dos Órgãos Municipais de Vigilância Sanitária do Estado do Rio de Janeiro. 
Os órgãos municipais, além de não possuírem condições mínimas para executarem suas ações, apresentam estrutura insuficiente para garantir a guarda segura de seus processos administrativos, pois alguns não têm sequer um arquivo para esse fim. Igualmente difícil se apresenta a situação em termos de transporte e de equipamento de informática, já que a falta desses meios para pesquisa, atualização normativa e registro, compromete seriamente a fiscalização sanitária.

Estes dados reforçam o discutido anteriormente, sobre a não-aplicação, por vários gestores municipais, dos recursos de transferência federal de incentivo as ações de VISA (PBVS) nos órgãos responsáveis por desenvolverem essas atividades. E enfatizam a importância do suporte estadual neste aspecto.

\section{HUMANOS}

As variáveis consideradas imprescindíveis para caracterizar um órgão de VISA como estruturado no requisito recursos humanos refere-se à composição da equipe multidisciplinar e sua capacitação. A SES-RJ, através da Portaria no 1.262/1998, definiu a composição ideal da equipe de VISA para o estado, evidenciando que o número de profissionais deve ser calculado de acordo com número, porte e diversidade de estabelecimentos sujeitos a VISA no território. Essa equipe multiprofissional deveria contar, além da presença do veterinário, que já era realidade nos municípios do estado, com médico, enfermeiro, farmacêutico e engenheiro ou arquiteto.

Para esta definição, parte-se do princípio de que a equipe de VISA necessita de profissionais que atuem como especialistas, para qualificar a resposta do órgão nos distintos ramos de atividades. O médico e o enfermeiro, como referência nas ações em serviços de saúde; o veterinário, na área de alimentos; e o farmacêutico, em medicamentos e afins. Propõe-se um processo de trabalho baseado na ação de especialistas que se aprofundam nos conhecimentos necessários a sua atuação, onde cada qual é referência em sua área.

A tabela 5 mostra resultados que ilustram a situação nesse aspecto. 


\begin{tabular}{lc}
\hline Composição da equipe multiprofissional & \% presença nos municípios \\
\hline Equipe Multiprofissional & 28 \\
Profissionais de nível superior efetivos & 80 \\
Pelo menos um médico veterinário na equipe & 95 \\
Pelo menos um farmacêutico na equipe & 57 \\
Municípios com atividades de capacitação & 17 \\
\hline Perfil do profissional de nível superior & \% entre total de profissionais \\
\hline Profissionais de nível superior do total de profissionais & 27 \\
Médico Veterinário entre as categorias profissionais & 49 \\
Farmacêutico entre as categorias profissionais & 09 \\
Profissionais capacitados entre o total de profissionais & 88 \\
\hline
\end{tabular}

Fonte: Elaborado a partir de: NPDI/CVS-SES-RJ, (2005; 2006). Diagnóstico Situacional dos Órgãos Municipais de Vigilância Sanitária do Estado do Rio de Janeiro.

Como visto, na proposta do CVS/SES-RJ para executar as ações descentralizadas, os órgãos municipais precisam de recursos humanos qualificados e em quantidade proporcional ao número e complexidade dos estabelecimentos sujeitos à fiscalização sanitária no território. No entanto, o quadro de pessoal dos órgãos municipais de VISA é crítico. A tabela 5 mostra que somente $28 \%$ dos municípios contam com equipe multiprofissional. Na composição desta, destacam os médicos veterinários, que estão presentes em $95 \%$ das equipes e representam $49 \%$ do total de profissionais de nível superior, seguidos dos farmacêuticos, presentes em 57\% das equipes, representado $9 \%$ do total. Esses dados também reforçam a informação presente nos documentos institucionais e nos dados de diagnósticos do CVS/SES-RJ, de que a fiscalização dos estabelecimentos de gêneros alimentícios ainda é uma função principal na VISA municipal.

Cabe atentar para o fato de que apenas $27 \%$ dos funcionários têm nível superior. No entanto, não foram verificadas nos documentos propostas de atuação e qualificação destinadas especificamente aos profissionais de nível médio.

Com o propósito de superar as deficiências de pessoal de nível superior, têm sido deslocados profissionais da rede de saúde para atividades de fiscalização em VISA, com dedicação de quatro horas semanais em média, segundo o porte do 
município. Essa decisão é fundamental em ações como as de inspeção em estabelecimentos farmacêuticos, onde a legislação determina a presença do profissional da área. Mesmo assim, é um paliativo que está muito aquém das necessidades, pois o técnico é destinado restritamente às ações de fiscalização sanitária com o intuito de respaldar técnica e legalmente a atuação do órgão, não estando disponível para interagir com a equipe.

Ainda em relação à capacitação dos recursos humanos, apesar de a tabela 5 mostrar que $88 \%$ dos profissionais têm sido capacitados para atuar na VISA, somente $17 \%$ dos municípios desenvolvem atividades de capacitação, o qual corrobora a importância de o órgão estadual assumir a responsabilidade de qualificar os profissionais de VISA como uma das estratégias de suporte ao processo de descentralização, essencial para harmonização dos conceitos e dos procedimentos de vigilância sanitária no SEVS. No entanto, os municípios de grande porte, e alguns médios, que reúnem o maior quantitativo de profissionais, têm iniciativas de qualificação de seus servidores, cabendo ao estado apenas ação complementar.

\section{FINANCEIROS}

Os recursos do TAM somam-se ao Piso de Atenção Básica (PAB variável) de VISAPBVS, correspondente, no período estudado, a $\mathrm{R} \$ 0,25$ (vinte e cinco centavos) por habitante/ano, perfazendo esses valores um total de $\mathrm{R} \$ 0,45$ per capita. No Estado do Rio de Janeiro, foram habilitados 11 municípios, os quais passaram a receber esses recursos, sendo os únicos que tiveram seus recursos ampliados, pois como visto, a implantação do Piso Básico Estadual de Vigilância Sanitária idealizado pelo CVS/SES-RJ nunca se concretizou.

Com exceção do município do Rio de Janeiro, que tem elevado potencial arrecadador, os demais municípios não disponibilizavam verba específica para o órgão de VISA. Nas atividades de campo, a posição observada é que os recursos federais destinados são insuficientes, sendo o nível local que arca com os gastos do setor. Mesmo assim, grande parte dos municípios não desenvolve atividades arrecadatórias, inexistindo taxa de VISA.

Em relação aos recursos federais, na maioria dos casos estes não são gerenciados pelo coordenador de vigilância sanitária e o setor não tem um plano de execução financeira para estes recursos. No levantamento feito junto aos municípios, no ano de 2002 chegava a quase um terço o número de 
coordenadores que desconheciam os recursos do PBVS destinados a seus municípios, sendo que, em 2006, a totalidade já conhecia, mesmo que alguns ainda tivessem dúvidas sobre o montante.

\section{Normas de acompanhamento e controle}

A fiscalização sanitária consiste na verificação da aplicação das normas sanitárias, com a finalidade de apontar as irregularidades que possam gerar agravos à saúde. A metodologia empregada para verificação das boas práticas na produção e circulação de bens e produtos é a inspeção sanitária, compreendida como um braço executor da agência reguladora nacional para constatar e promover a aderência à legislação sanitária vigente (ROZENFELD; 2000).

A inspeção sanitária é realizada de acordo com roteiros que contêm os principais pontos a serem observados na visita ao local e apresentam os critérios de avaliação dos estabelecimentos. Seu propósito é promover a harmonização da fiscalização sanitária e possibilitar uma visão sinóptica dos principais problemas do estabelecimento inspecionado.

Dos dados coletados na inspeção, resulta um diagnóstico que permite orientar as negociações com os afetados, estabelecer um cronograma de superação das irregularidades detectadas e sensibilizar os envolvidos e a comunidade quanto às consequências sociais do problema. Nesse processo são aplicados os termos oficiais para que o órgão de VISA notifique o estabelecimento e aplique, se necessário, as sanções previstas nas normas sanitárias nacionais, vigentes desde a Lei no 6.437, de 1977, a qual também relaciona os documentos pertinentes (Termo de Visita; Termo de Apreensão e Inutilização de Produtos; Auto de Infração, etc.) e estipula a aplicação dos mesmos. Ao término da intervenção, os procedimentos são registrados no Relatório de Inspeção, fundamentado na legislação.

A tabela 6 , abaixo, relativa às atividades de inspeção, mostra o percentual de municípios que aplicam os instrumentos de fiscalização padronizados. 
Tabela 6. Padronização e registro de inspeções nos municípios do Estado do Rio de Janeiro, 2005-2006

\begin{tabular}{lc}
\hline \multicolumn{1}{c}{ Instrumentos } & $\begin{array}{c}\text { \% de } \\
\text { municípios }\end{array}$ \\
\hline Instrumento para registro de atividades & 76 \\
Termos oficiais & 74 \\
Cadastro dos estabelecimentos sujeitos a controle & 73 \\
Processos administrativos próprios & 57 \\
Roteiros de inspeção utilizados & 55 \\
Cadastro dos estabelecimentos informatizados & 41 \\
Rotina de trabalho instituída & 30 \\
Protocolo próprio & 27 \\
\hline
\end{tabular}

Fonte: Elaborado a partir de: NPDI/CVS-SES-RJ, (2005; 2006). Diagnóstico Situacional dos Órgãos Municipais de Vigilância Sanitária do Estado do Rio de Janeiro.

Os dados acima discriminados são críticos na medida em que somente cerca da metade (55\%) dos órgãos municipais realiza as inspeções sob orientação de um roteiro que garanta a harmonização dos procedimentos, embora $74 \%$ tenham disponíveis os termos oficiais e $73 \%$ conheçam os estabelecimentos existentes em seu território por terem organizado o cadastro daqueles sujeitos ao seu controle. No entanto, apenas $41 \%$ dos municípios contam com informações informatizadas, o que revela a predominância de práticas manuais nesse campo, embora se disponha de computadores.

Apesar de 76\% dos municípios possuírem instrumento para registro de suas atividades, podendo gerar relatórios técnicos que permitam definir prioridades para o monitoramento da situação sanitária dos estabelecimentos no nível local, $70 \%$ atuam por denúncias, já que não possuem rotina de trabalho instituída. Ademais, somente $57 \%$ dos órgãos municipais têm a propriedade de seus processos administrativos, ou seja, podem assegurar o devido sigilo e segurança, ficando os outros $43 \%$ legalmente descobertos por não atenderem às exigências mínimas para o exercício da fiscalização sanitária. 
As informações provenientes das atividades de fiscalização sanitária devem alimentar um sistema local de informações de vigilância sanitária, mesmo levando em conta as dificuldades existentes na implantação do Sistema Nacional de Informação em VISA. Todavia, as informações analisadas comprovam a precariedade deste procedimento, que é definitivo para que o SNVS venha a ter um diagnóstico mais preciso de suas necessidades.

\section{Ações realizadas}

A tabela 7 reitera que a maior prestação de serviços de VISA nos municípios é no comércio de alimentos, dado que $78 \%$ dos órgãos executam fiscalizações nesse ramo, fato que, por sua vez, tem correspondência com a ênfase dada na descentralização à transferência dessas ações aos municípios.

\section{Tabela 7. Açóes de VISA executadas nos municípios do Estado do Rio de Janeiro, 2005-2006}

\begin{tabular}{ll}
\hline \multicolumn{1}{c}{ Ações } & $\%$ \\
\hline Ações educativas & 80 \\
Inspeção sanitária em comércio de alimentos & 78 \\
Monitoramento da qualidade da água (coleta de amostra) & 74 \\
Inspeção sanitária em outros serviços & 68 \\
Material educativo publicado & 58 \\
Inspeção sanitária em comércio de medicamentos & 55 \\
Inspeção sanitária em serviços de saúde & 37 \\
Qualidade de alimentos (coleta de amostras) & 37 \\
\hline
\end{tabular}

Fonte: Elaborado a partir de: NPDI/CVS-SES-RJ, (2005; 2006). Diagnóstico Situacional dos Órgãos Municipais de Vigilância Sanitária do Estado do Rio de Janeiro.

Os dados também ilustram o baixo número de açōes relativas à coleta de amostras de alimentos e inspeção sanitária em serviços de saúde. Além do expressivo percentual (45\%) de municípios que não executam ações no comércio de medicamentos, é preocupante que em $63 \%$ dos municípios não exista inspeção sanitária em serviços de saúde. No processo de descentralização, a baixa cobertura das ações de VISA é evidenciada e estratégias para superação do problema passam a ser debatidas. 
Contudo, a população ainda está exposta a variados riscos, devido à baixa cobertura do controle de produtos e serviços. Sobre a persistência destes problemas e as demais deficiências acima constatadas, a insuficiência de recursos financeiros foi um fator que influiu de forma decisiva, em particular, o descumprimento, por parte da SES-RJ, dos compromissos pactuados quanto ao apoio financeiro e o repasse de recursos materiais. Mas foi possível também perceber outros importantes impedimentos, como: insuficiente estruturação do órgão municipal, baixa capacidade de planejamento e gestão persistentes no nível local, alta rotatividade dos profissionais da área e a forte influência político-econômica no setor, principalmente no pequeno município. As relações de parentescos entre representantes do executivo e do legislativo e os comerciantes e produtores em municípios de pequeno porte foi apresentado como problema para o desenvolvimento das ações de VISA em diversos encontros promovidos pelo CVS/ SES-RJ com os órgãos municipais.

No entanto, uma questão comumente apresentada como entrave ao processo de descentralização, a relação conflituosa entre estados e municípios, principalmente os das capitais das unidades federadas e os governos de Estado da federação (SOUTO, 2004), foi minimizada com as estratégias desenvolvidas pelo CVS/ SES-RJ, que impunham a constante negociação entre gestores, com espaço sistêmico de decisão e qualificação dos componentes do SEVS.

\section{Conclusões}

O propósito desta exposição foi mostrar a complexidade envolvida na descentralização das ações de VISA no Estado do Rio de Janeiro e apontar pontos fortes e fracos nesse processo. Em primeiro lugar, destaca a relevância da entrada em cena da ANVISA, em 2000, e seu papel primordial no desenho e montagem do Sistema Nacional de Vigilância Sanitária (SNVS), cujo desenvolvimento avança a passos lentos, porém seguros, graças à interlocução com uma ampla gama de atores e suas indispensáveis contribuições para levar adiante esse magno empreendimento.

No âmbito da SES-RJ, no período estudado houve, sem dúvida, avanços significativos em diferentes frentes, a começar pela estruturação do órgão de VISA, além da produção de conhecimentos, a capacitação profissional e o estabelecimento de articulaçôes dinâmicas com os gestores dos municípios, o que redundou no fortalecimento do SEVS em geral. No entanto, a este propósito vale lembrar que o 
processo de descentralização tinha sido iniciado timidamente com a implantação do SUS nos começos dos anos 1990, ganhando decisivo impulso somente a partir do repasse de recursos financeiros da ANVISA nos começos da presente década de 2000, fato este que tornou possíveis os progressos assinalados.

Em relação aos municípios, a SES-RJ fez importantes investimentos no apoio à descentralização da VISA, mas os avanços foram muito tímidos. E isto pode ser atribuído a diversos condicionantes, como a tradição centralizadora e burocratizada dessa secretaria, seu baixo poder regulador e a renitência em contribuir financeiramente com os municípios, além da precária situação preexistente no nível local. Em outras palavras, essas falhas revelam as limitações da cooperação solidária no Rio de Janeiro entre o estado e municípios em componentes cruciais para a expansão descentralizada e a melhoria substantiva da vigilância sanitária no estado, dentre os quais se destacam os recursos financeiros, cujos repasses não foram efetivados, e o logístico, entravado pela ineficiência administrativa. Além disso, se hão de considerar as rotineiras descontinuidades nas políticas públicas cada vez que mudam os governos estadual e municipais e, não menos importante, a interferência de interesses privados contrários a uma rigorosa fiscalização sanitária, seja porque afetaria seus negócios, seja por razões puramente clientelísticas.

É assim como, apesar das diretrizes da ANVISA e os compromissos pactuados com os estados para tornar realidade o SNVS no Estado do Rio de Janeiro, não ocorreram transformações significativas nas funções de VISA, pois a SES-RJ continua executando em grande escala as ações de alta e média complexidades, em detrimento do novo papel coordenador e assessor atribuído aos estados, enquanto os municípios, ainda que por vezes precariamente, permanecem centrados nas ações básicas, em particular, a fiscalização no ramo alimentício. A precariedade das ações locais da VISA é muito preocupante porque expõe a saúde dos cidadãos a sérios riscos.

Com respeito às avaliações que fundamentaram este estudo, há de se assinalar que, não obstante a competência técnica demonstrada na elaboração da metodologia e dos diagnósticos, os relatórios revelam que aquelas não foram precedidas de um mapeamento acurado do panorama do estado como um todo. Com efeito, o território estadual é muito heterogêneo em todas as dimensões indispensáveis para o planejamento e a implantação de políticas e programas, a começar pela concentração de dois terços da população na Região Metropolitana, enquanto a maioria dos municípios é de pequeno porte e carente de recursos de toda ordem; as disparidades 
socioeconômicas entre regiões e dentro delas; a nivelação dos municípios segundo um mesmo padrão avaliativo em circunstâncias em que há cidades com recursos suficientes para realizar uma boa vigilância sanitária, a começar pelo Rio de Janeiro e Niterói. Em suma, teria sido necessário hierarquizar previamente os municípios, a fim de a SES-RJ focalizar os esforços naqueles mais necessitados de apoio.

Para encerrar, cabe reiterar que a implantação do SNVS de forma descentralizada ainda é um processo em curso, cujo avanço mais firme depende de um ordenamento legal mais apurado e de uma série de ajustes, sobretudo no que concerne ao gradiente de atribuições e responsabilidades nos três níveis de governo e, dentro de cada um destes, a adequada localização institucional da VISA no organograma político-administrativo das secretarias de saúde, a fim de que possam contar com recursos de poder condizentes com a relevância das suas funções na proteção da saúde da população.

\section{Referências}

ARRETCHE, Martha T. J. Federalismo e Políticas Sociais: problemas de coordenação e autonomia. In: FERRAREZI, Elisabete (Org.). Políticas Públicas. v. 2. Brasília: Enap, 2006. p. 91-110.

. Mitos da descentralização: mais democracia e eficiência nas políticas públicas? Revista Brasileira de Ciências Sociais, n. 31, v. 11, p. 44-66, 1996.

. Tendências no estudo sobre avaliação. In: RICO, Elizabeth Melo (Org.). Avaliação de políticas sociais: uma questão em debate. 2 ed. São Paulo: Cortez, 1999.

BODSTEIN, Regina. Atenção Básica na Agenda da Saúde. Revista Ciência e Saúde Coletiva, v. 7 , n. 3, São Paulo, 2002.

BRASIL. Senado Federal. Constituição da República Federativa do Brasil. Brasília: Senado Federal, 1988. BRASIL. Ministério da Saúde. Lei no 8080, de 19 de setembro de 1990. Dispóe sobre as condições para a promoção, proteção e recuperação da saúde, a organização e o funcionamento dos serviços correspondentes e dá outras providências. Diário Oficial da Uniāo, Brasília, p. 18.055, set. 1990.

. Lei no 8142, de 28 de dezembro de 1990. Dispóe sobre a participação da comunidade na gestão do Sistema Único de Saúde (SUS) e sobre as transferências intergovernamentais de recursos financeiros na área da saúde e dá outras providências. Diário Oficial da União, Brasília, p. 25.694, dez. 1990 .

. Lei no 9.782, de 26 de janeiro de 1999. Define o Sistema Nacional de Vigilância Sanitária, cria a Agência Nacional de Vigilância Sanitária, e dá outras providências. Diário Oficial da Uniāo, Brasília, jan. 1999. 
BRASIL. Agência Nacional de Vigilância Sanitária. Cartilha de Vigilância Sanitária. Disponível em: http://www.anvisa.gov.br/institucional/snvs/coprh/cartilha.pdf Acesso em: 13 fev. 2007

- Agência Nacional de Vigilância Sanitária. Censo Nacional dos Trabalhadores da Vigilância Sanitária, 2004. Disponível em http://www.anvisa.gov.br/hotsite/censo_2004. Acesso em: 23 abr. 2005.

. Agência Nacional de Vigilância Sanitária. Conferência Nacional de Vigilância Sanitária, 1. Efetivar o Sistema Nacional de Vigilância Sanitária: Proteger e promover a saúde, construindo cidadania. Relatório Final... Brasília, DF: ANVISA, 2001.

. Agência Nacional de Vigilância Sanitária. Plano Diretor de Vigilância Sanitária. Brasília: ANVISA, 2007.

Agência Nacional de Vigilância Sanitária. Portaria no 2.473, de 29 de dezembro de 2003. Estabelece as normas para a programação pactuada das ações de vigilância sanitária no âmbito do Sistema Único de Saúde, fixa a sistemática de financiamento e dá outras providências. Diário Oficial da União, Brasília, jan. 2004.

. Portaria no 1.565 , de 26 de agosto de 1994. Define o Sistema Nacional de Vigilância Sanitária e sua abrangência, esclarece a competência das três esferas de governo e estabelece as bases para a descentralização da execução de serviços e ações de vigilância em saúde no âmbito do SUS. Diário Oficial da União, Brasília, DF, ago. 1994.

. Portaria no 18, de 26 de janeiro de 1999. Inclui os componentes de Tipo de Prestador, Tipo de Atendimento e Grupo de Atendimento associados aos respectivos procedimentos, conforme especificado no Anexo I. Diário Oficial da Uniāo, Brasília, fev. 1999.

. Portaria no 1.882, de 18 de dezembro de 1997. Estabelece o Piso da Atenção Básica PAB e sua composição. Diário Oficial da União. Brasília, dez. 1997.

. Portaria no 399, de 22 de fevereiro de 2006. Divulga o Pacto pela Saúde 2006 Consolidação do SUS - e aprova as Diretrizes Operacionais do Referido Pacto. Diário Oficial da União, Brasília, fev. 2006.

COHEN, Mirian M.; LIMA, Juliano; ANDRADE, Claudia R. Vigilância Sanitária nas normas regulamentadoras do SUS. In: SETA, M. H. D. et al. (Org.). Gestão e Vigilância Sanitária: modos atuais de pensar e fazer. Rio de Janeiro: Fiocruz, 2006.

COHEN, Mirian M.; MOURA, Maria de Lourdes O.; TOMAZELLI, Jeane. Descentralização das ações de Vigilância Sanitária nos municípios em Gestão Plena no Estado do Rio de Janeiro. Revista Brasileira de Epidemiologia, v. 7, n. 3, p. 290-301, 2004.

COSTA, Ediná A. Vigilância Sanitária: proteção e defesa da saúde. São Paulo: Sobravime, 2004. 
INSTITUTO BRASILEIRO DE GEOGRAFIA E ESTATÍSTICA. População recenseada e estimada, segundo os municípios - Rio de Janeiro, 2007. Disponível em http://www.ibge.com.br/ home/estatistica/populacao/contagem2007/RJ.pdf Acesso em: 27 fev. 2008.

LUCCHESE, Geraldo. Globalização e regulação sanitária. Os rumos da Vigilância Sanitária no Brasil. Tese (Doutorado em Saúde Pública) - Escola Nacional de Saúde Pública, Fundação Oswaldo Cruz, Rio de Janeiro, 2001.

LUCCHESE, Patrícia R. T. A Vigilância Sanitária, segundo as normas operacionais básicas do Ministério da Saúde. In: ROZENFELD, Suely (Org.). Fundamentos da Vigilância Sanitária. Rio de Janeiro: Fiocruz, 2000.

MENDES, E. V. Os grandes dilemas do SUS. v. 2. Salvador: Casa da Qualidade, 2001.

PIOVESAN, Márcia F. et al. Vigilância sanitária: uma proposta de análise dos contextos locais. Revista Brasileira de Epidemiologia, Rio de Janeiro, 2005.

RIBEIRO, Patrícia T. Direito à Saúde: integridade, diversidade e territorialidade. Ciência \& Saúde Coletiva, v. 12, p. 1.525-1.532, 2007.

RIO DE JANEIRO (ESTADO). Núcleo de Planejamento e Desenvolvimento Institucional do Centro de Vigilância Sanitária. Secretaria de Estado de Saúde do Rio de Janeiro. Diagnóstico Situacional dos Órgãos Municipais de Vigilância Sanitária do Estado do Rio de Janeiro. Rio de Janeiro: SES, 2002 (mimeo).

Núcleo de Planejamento e Desenvolvimento Institucional do Centro de Vigilância Sanitária. Secretaria de Estado de Saúde do Rio de Janeiro. Diagnóstico Situacional dos Órgãos Municipais de Vigilância Sanitária do Estado do Rio de Janeiro. Rio de Janeiro: SES, 2005 (mimeo).

. Núcleo de Planejamento e Desenvolvimento Institucional do Centro de Vigilância Sanitária. Secretaria de Estado de Saúde do Rio de Janeiro. Diagnóstico Situacional dos Órgãos Municipais de Vigilância Sanitária do Estado do Rio de Janeiro. Rio de Janeiro: SES, 2006 (mimeo).

Núcleo de Planejamento e Desenvolvimento Institucional do Centro de Vigilância Sanitária. Secretaria de Estado de Saúde do Rio de Janeiro. Relatório de acompanhamento das açôes descentralizadas (Faz não Faz). Rio de Janeiro: SES, 2005. Versão Revisada (mimeo).

Núcleo de Planejamento e Desenvolvimento Institucional do Centro de Vigilância Sanitária. Secretaria de Estado de Saúde do Rio de Janeiro. Relatório de Gestão do Centro Estadual de Vigilância Sanitária. Rio de Janeiro:S ES, 2006 (mimeo).

. Núcleo de Planejamento e Desenvolvimento Institucional do Centro de Vigilância Sanitária. Secretaria de Estado de Saúde do Rio de Janeiro. Questionário de supervisão das ações descentralizadas de Vigilância Sanitária do Estado do Rio de Janeiro. Rio de Janeiro: SES, 2006. Versão revisada (mimeo) 
RIO DE JANEIRO (ESTADO). Secretaria de Estado de Saúde. Resolução SES no 1.262, de 02 de fevereiro de 1998. Delega competência de ações de vigilância sanitária de estabelecimentos de interesse à saúde pública. Rio de Janeiro, 2005.

. Secretaria de Estado de Saúde. Resolução SES no 2.655, de 02 de fevereiro de 2005. Delega competência de açôes de vigilância sanitária de estabelecimentos de interesse à saúde pública. Rio de Janeiro, 2005.

ROZENFELD, Suely (Org.). Fundamentos da Vigilância Sanitária. Rio de Janeiro: Fiocruz, 2000. SOUTO, Ana Cristina. A Vigilância Sanitária no Brasil. São Paulo: Sobravime, 2004. 


\section{Dilemmas of the process of decentralized management of health surveillance in Rio de Janeiro State}

With the creation of the Unified Health System in 1990, the Ministry of Health has taken the first steps to decentralize health surveillance actions, which meant a decisive innovation in the traditional institutional framework in this area and challenge for managers at all three levels of the Federation. The effects of this determination were felt only after the creation of the National Sanitary Surveillance Agency, in late 1999, when it was possible to structure the current National System of Sanitary Surveillance in a design that encourages the role director, coordinator and executor of the more complex actions of the State Health Secretariats. This study analyzes the decentralization of management of VISA undertaken by the State Secretariat of Health of Rio de Janeiro between 2002-2006 and the conditions of the municipal acting in their duties by providing research-based analysis of reports evaluation of decentralization developed by the Center for Health Surveillance. Among the findings, it highlights the fragility of the State Health Secretariat to shoulder the burden assigned to it and issues underlying the performance hall. These findings reflect the many difficulties in intergovernmental relations on the need for parties to act jointly in a key area for the individual and collective health and welfare of the population. The study states the basic requirements of the process of structuring a body of VISA and makes an important contribution to better understand the political barriers, institutional, technical, material and human challenge to managers, to implement the innovations occasioned by decentralization in this complex field.

Key words: Unified Health System; health surveillance; decentralization. 